\title{
ALONSO CANO, ARQUITECTO ARTISTA
}

\author{
POR \\ ALFONSO RODRÍGUEZ G. DE CEBALLOS \\ Universidad Autónoma de Madrid
}

All facets of Alonso Cano's architectural works are examined: architectural altarpieces, drawings for altarpieces, drawings for architectural ornamentation, and constructed edifices in Granada. The author concludes that Cano's originality and his greatest contribution lies in his command of architectural ornamentation.

Desde la celebración del centenario de la muerte de Cano, que dio lugar a una importante exposición y un coloquio entre especialistas en Granada el año 1967, hasta la conmemoración ahora de su nacimiento han transcurrido treinta y cuatro años ${ }^{1}$. En este largo período se han publicado algunos, no muchos, artículos y estudios sobre su proteica y calidoscópica personalidad, pero escasísimos sobre su faceta de arquitecto, pese a que en buena parte su fama ha estribado en la singularidad con que dominó y ejerció las tres artes llamadas mayores, pintura, escultura y arquitectura ${ }^{2}$.

Con todo en 1983 se produjo un acontecimiento capital para el conocimiento del artista granadino: la traducción al castellano de la monografía de Harold H. Wethey, aparecida en inglés veintiocho años antes, la segunda monografía en abordar la obra total de Cano después de la de Manuel Martínez Chumillas de 1948. El estudioso norteamericano aprovechó la ocasión para revisar, aumentar y poner al día sus apreciaciones, si bien el capítulo dedicado a la arquitectura fue el menos retocado ${ }^{3}$. Un replanteamiento de Cano como arquitecto llegó en 1975 de la mano del inglés hispanizado René Taylor quien, escribiendo a propósito del maestro de obras José Granados de la Barrera, pasó minuciosa y sagaz revista a las últimas construcciones del artífice durante su última etapa granadina, deshaciendo tópicos arraigados en la tradición y estableciendo el verdadero alcance de Cano como arquitecto ${ }^{4}$.

\footnotetext{
1 Centenario de Alonso Cano en Granada. Tomo I: Estudios, Patronato de la Alhambra y Generalife, Caja de Ahorros de Granada, Granada 1970.

2 Un ensayo de bibliografía sobre Alonso Cano en el último siglo, de 1901 a 2001 , ha sido publicado por J. Galisteo y otros con el título «Aproximación bibliográfica a Alonso Cano y su escuela» en Cuadernos de Arte. Universidad de Gra nada, n. 32,2001, pp. 377-400.

${ }^{3}$ Harold $\mathrm{H}$. Wethey, Alonso Cano. Pintor, escultor y arquitecto, traducción de Ramiro Palencia, Alianza Forma, Madrid 1983. Véase la interesante reseña de este libro hecha por Nina Ayala Mallory, «Noticias de Alonso Cano», Goya, n 180 1984 , pp. $347-49$.

4 René Taylor, «El arquitecto José Granados de la Barrera», Cuadernos de Arte de la Universidad de Granada, ${ }^{\circ} 22$, 1975, pp. $5-14$
} 
Con motivo de la restauración del cuadro de la Virgen del Rosario en la catedral de Málaga la Fundación Argentaria tomó el excelente acuerdo de organizar un simposio sobre nuestro personaje, en el que interviniesen distintos especialistas, como hacía años en Granada. La publicación de las intervenciones en 1998 ha constituido una aportación muy valiosa, aun sin pretender ser sistemática y completa, a la profundización del conocimiento del artista; en ella cuatro de los artículos se centran en varios aspectos de su quehacer arquitectónico ${ }^{5}$. No debe pasarse por alto aquí el hallazgo casi milagroso en Valencia del inventario de la librería de Cano, que se suponía definitivamente perdido y que fue ofrecido en primicias en 1995. Librería que ha puesto de relieve, como era de esperar, la enorme curiosidad de nuestro hombre por materias y asuntos de todo tipo, no sólo artísticos, y, desde luego y muy en primer término, por los tratados de arquitectura y ciencias auxiliares y afines ${ }^{6}$.

Tampoco debe silenciarse la reciente exposición de los dibujos de Alonso Cano ofrecida por el Museo del Prado como adelanto de otras que se preparan en Granada y en otros lugares. El catálogo, aunque no definitivo al eludir la discusión sobre la genuina autoría de varios de los diseños expuestos, ha servido para recoger, en todo caso, la casi práctica totalidad de ellos y, desde luego, los numerosos de retablos, proyectos arquitectónicos y pormenores ornamentales a los que se ha dedicado uno de los estudios preliminares ${ }^{7}$. Finalmente la revista Cuadernos de Arte, de la Universidad de Granada, acaba de consagrar su último número casi monográficamente a la vida y obra de Cano, iniciando así las celebraciones del cuarto centenario de su nacimiento. En él he escrito un extenso artículo sobre su actividad arquitectónica; aquí retomaré datos e ideas que allí expuse, combinándolos con otros espigados de las últimas publicaciones acerca del artista ${ }^{8}$.

Lo que Alonso Cano aportó a la arquitectura barroca española del xvir se puede escindir en tres apartados: los retablos, los dibujos arquitectónicos y decorativos y los edificios efectivamente construidos. Como denominador común a todos ellos estaría la originalidad y atrevimiento con que manipuló los órdenes arquitectónicos y sus proporciones canónicas, y la acusada inventiva en los ornatos con que revistió retablos, proyectos dibujados y construcciones realizadas. En este último aspecto destacarían las placas recortadas y superpuestas y la llamada «hoja canesca», una suerte de cogollo vegetal que se distingue de las tradicionales hojas de acanto y de las guirnaldas y sartas de frutas habituales en el barroco del Seiscientos. El argumento de la originalidad canesca se encontraría en estas frases de Lázaro Díaz del Valle, el primer biógrafo contemporáneo de Cano, que repetiría más adelante también Antonio Palomino: «Hizo de esta profesión (arquitectura) el arco triunfal que tocó a los mercaderes en la puerta de Guadalajara en la entrada y suntuoso recibimiento de la serenísima S.N. Doña Mariana de Austria..., obra de tan nuevo usar de los miembros y proporciones de la arquitectura que admiró a todos los demás artífices porque se apartó de la manera que hasta estos tiempos habían seguido los de la antigüiedad» ${ }^{9}$.

El dibujo correspondiente a dicho arco de triunfo no se ha conservado y, por consiguiente, nos es imposible aquilatar hasta qué punto fue tan radicalmente novedoso en la alteración de miembros y proporciones clásicas de los órdenes de la arquitectura. De todas maneras las

\footnotetext{
s Figuras e imágenes del Barroco. Estudios del Barroco español y sobre la obra de Alonso Cano. Fundación Argentaria, Visor, Madrid 1999, pp. 211-342.

6 Benito Navarrete Prieto, «Sobre Vicente Salvador Gómez y Alonso Cano», Ars Longa. Cuadernos de Arte, n 6, 1995, pp. 133-40.

7 Alonso Cano. Dibujos, Catálogo de la Exposición, Museo Nacional del Prado, Madrid 2001.

8 Alfonso Rodríguez G. de Ceballos, «En torno a Alonso Cano, arquitecto», Cuadernos de Arte. Universidad de Granada, IV Centenario de Alonso Cano, n. 32,2001 , pp. 85-103.

9 Epílogo y nomenclatura de algunos artífices..., en F. J. Sánchez Cantón, Fuentes literarias para la Historia del Arte Español, II, Bermejo impresor, Madrid 1933, p.338.
} 
palabras de Díaz del Valle suenan a hipérbole retórica, tan habitual en el género de hagiografía más que de biografía de artistas. La relación de la entrada en 1649 de la reina Mariana de Austria, debida a la pluma del erudito don Lorenzo Ramírez del Prado y publicada en 1650 , no manifestó especial admiración por el mencionado arco ${ }^{10}$. Por su parte el gongorino poeta Juan Enebro y Andía sólo acertó a dedicarle esta alabanza excesivamente genérica e inconcreta donde, además, parece querer resaltar más sus cualidades escultóricas que arquitectónicas:

\author{
«Otro arco en Guadalajara \\ de puerta le dan el ayre \\ y mirando el verde al blanco \\ con el acierto le sale... \\ Más ser a la arquitectura \\ no pudo Lisipo darle \\ y el mármol quedó hecho un mármol \\ viendo que le vence el arte» ${ }^{11}$.
}

Pienso de entrada que la personalidad de Cano como arquitecto se nos escapa y volatiliza si con la palabra arquitecto nos atenemos al sentido más preciso y riguroso del término: es decir a una persona que no sólo sabe dibujar en el papel arquitectura, sino acotarla con sus medidas exactas y pitipiés, realizar su correcta cimentación, dominar su albañilería y cortes de cantería para elevar sus muros y cerrar sus arcos y bóvedas. En este sentido estricto Cano no fue arquitecto ni probablemente pretendió serlo, pues carecía de la necesaria preparación para ello. Su padre Miguel Cano le enseñó el arte de hacer retablos, pero una cosa era encajar y encolar las piezas de madera que los componen y otra muy diferente manejar los duros y pesados materiales de la construcción cuya solidez para mantenerse en equilibrio estático requería otro tipo de conocimientos. Miguel Cano, eso sí, instruiría a su hijo en el dibujo e incluso le enseñaría a dibujar no sólo bidimensionalmente sino en perspectiva. Además el dibujo lo perfeccionó Alonso en el taller de Pacheco. Salió así uno de los dibujantes más finos, sensibles, primorosos y fecundos de toda la pintura del Seiscientos español. Por eso supo dotar a sus diseños de retablos y arquitectura de «adornos y galas de recuadros, cartelas, tarjas, ornatos caprichosos, bizarría de remates, festones, grutescos, mascarones, serafines y otras mil galas que usan los pintores y escultores», gracias a todo lo cual, según Pacheco, el pintor dibujante y adornista aventaja y tiene preferencia sobre el arquitecto técnico y profesional ${ }^{12}$.

Alonso Cano fue, pues, en el marco de la polémica que en el transcurso del siglo XVII enfrentó a los arquitectos con los pintores, un arquitecto artista, no un puro técnico de la arquitectura. Por eso, más tarde y a ejemplo de Cano, esta modalidad de arquitecto, que se inmiscuía e incluso usurpaba a veces el puesto del profesional de la construcción, se impuso y acabó triunfando, y así Antonio Palomino atribuyó a Herrera Barnuevo, Herrera el Mozo, Jiménez Donoso y Claudio Coello edificios de Madrid que ellos contribuyeron a engalanar con los primores ornamentales propios de su habilidad e inventiva dibujística, pero que en rea-

10 J. Varey y A. M. Salazar, «Calderón de la Barca and the Royal Entry of 1649», Hispanic Review, Filadelfia, 1966, pp. 1-26; John Varey, «Motifs antiques dans l'Entrée de Marianne d’Autriche á Madrid en 1649», Actes des Journées Internationales d'Etude du Baroque, Montauban 1972, pp. 89-95.

$"$ Espléndido aparato... a la entrada de la ínclita Reyna nuestra señora Mariana de Austria, reproducido por José Simón Díaz, Relaciones de actos públicos celebrados en Madrid (1545-1649), Instituto de Estudios Madrileños, Madrid 1982, p. 507.

12 F. Pacheco, Arte de la Pintura, edición de B. Bassegoda, Cátedra, Madrid 1990, p.394. 
lidad de verdad habían sido proyectados y levantados de cimientos por maestros de obra profesionales ${ }^{13}$.

En esta coyuntura no es de extrañar que cuando Cano en 1643, a raíz de la caída en desgracia del conde-duque de Olivares, su protector, para tener un oficio seguro y fijo solicitó la plaza vacante del aparejador del Alcázar de Toledo, un arquitecto profesional, como Juan Gómez de Mora, se opusiese a ello con las siguientes palabras: «Alonso Cano, pintor grande en esta facultad, traza todo género de retablos y otras obras de ensamblaje y adornos con gran primor, pero no ha tratado en obras de calidad de las que hoy tiene el Alcázar de Toledo y se pueden ofrecer en los demás Alcázares y Casas de Vuestra Majestad, que tal vez la persona que tiene este oficio (de aparejador) es mandado acudir a dar su parecer, valiéndose de su persona en cosas del servicio de Vuestra Majestad» ${ }^{14}$.

De todas formas Cano parece haberse interesado particularmente por la arquitectura pura, adquiriendo tratados y libros técnicos cuya lectura y manejo supliese su carencia de conocimientos en esta materia. Su librería, cuyo inventario ha sido descubierto recientemente ${ }^{\text {is }}$, lo pone de relieve, toda vez que contenía —en caso similar al de Velázquez- tantos o más libros de arquitectura y ciencias auxiliares que de pintura o escultura. Tenía un Vitrubio en italiano, el comentario a éste de Daniel Barbaro, un Serlio, un Alberti, los tratados de Vignola, Palladio, Pietro Cataneo, Antonio Labaco, Viola y Tusconi, la Medidas del Romano de Sagredo, la Varia Conmesuración de Arfe, el Arte y Uso de Arquitectura de fray Lorenzo de San Nicolás. Poseía además escritos sobre fortificación y arquitectura militar, como el del capitán Cristóbal de Rojas, y algunas otras obras de geometría, matemáticas, náutica y cosmografía. La simetría y la perspectiva habían apasionado a nuestro artista desde los años de su formación junto a su padre, como lo atestigua Díaz del Valle, y así tenía libros de Durero, de Vignola y Sirigati sobre estos asuntos. ¿Cuándo comenzó Cano a adquirir esta batería de libros? Es posible que ya desde su primera etapa sevillana, aunque es más probable que lo hiciera a partir de su establecimiento en la corte madrileña y más exactamente hacia 1643 , cuando solicitó la vacante de aparejador del Alcázar toledano. En todo caso cuando más falta le hicieron los tratados de arquitectura, a saber cuando hubo de construir no sobre el papel sino en la realidad durante el último período de su vida en Granada, no pudo hechar mano de ellos pues los había depositado en la hospedería en Valencia de la cartuja de Porta Coeli, adonde los reclamó en su testamento acaso para venderlos y liquidar con su precio las deudas de que se veía acosado.

Los retablos que ensambló realmente Alonso Cano fueron muy escasos y todos en su primera fase sevillana, cuando contaba con la asistencia de su padre, con los oficiales de su taller e incluso con el local apropiado para hacerlo. En cambio cuando se trasladó a Madrid todo eso desapareció y mucho más cuando, a la muerte de su padre en 1644, se disolvió el taller de Sevilla. Acaso esta circunstancia explique el que los retablos que proyectó durante su larga permanencia en la corte no pasasen del papel. Es igualmente verosímil que Cano, persuadido y consciente de su valía y capacidad inusitadas como dibujante, se atuviese a la fase duramente ideativa y proyectiva de los retablos, dejando en manos de subalternos su realización manual y mecánica. Si así fue podríamos considerar su actitud y comportamiento como absolutamente modernos, propios de un artista para quien el oficio de tal es puramente mental y no manual.

13 Véase al respecto Alfonso Rodríguez G. de Ceballos, «L'architecture baroque espagnole vue á travers le débat entre architectes et peintres», Revue de l'Art, n. ${ }^{\circ} 70,1985$, pp. 41-52; Beatriz Blanco Esquivias, «Sobre el debate entre arquitectos profesionales y arquitectos artistas en el barroco madrileño. Las posturas de Herrera Barnuevo, Herrera el Mozo, Olmo y Ardemans», Espacio, Tiempo, Forma, U.N.E.D., serie VII, n. ${ }^{\circ} 4,1991$, pp. $20-34$.

14 Juan José Martín González, «Arte y artistas del siglo Xvil en la corte», A.E.A., XXXI, 1958, pp. 125-28. 

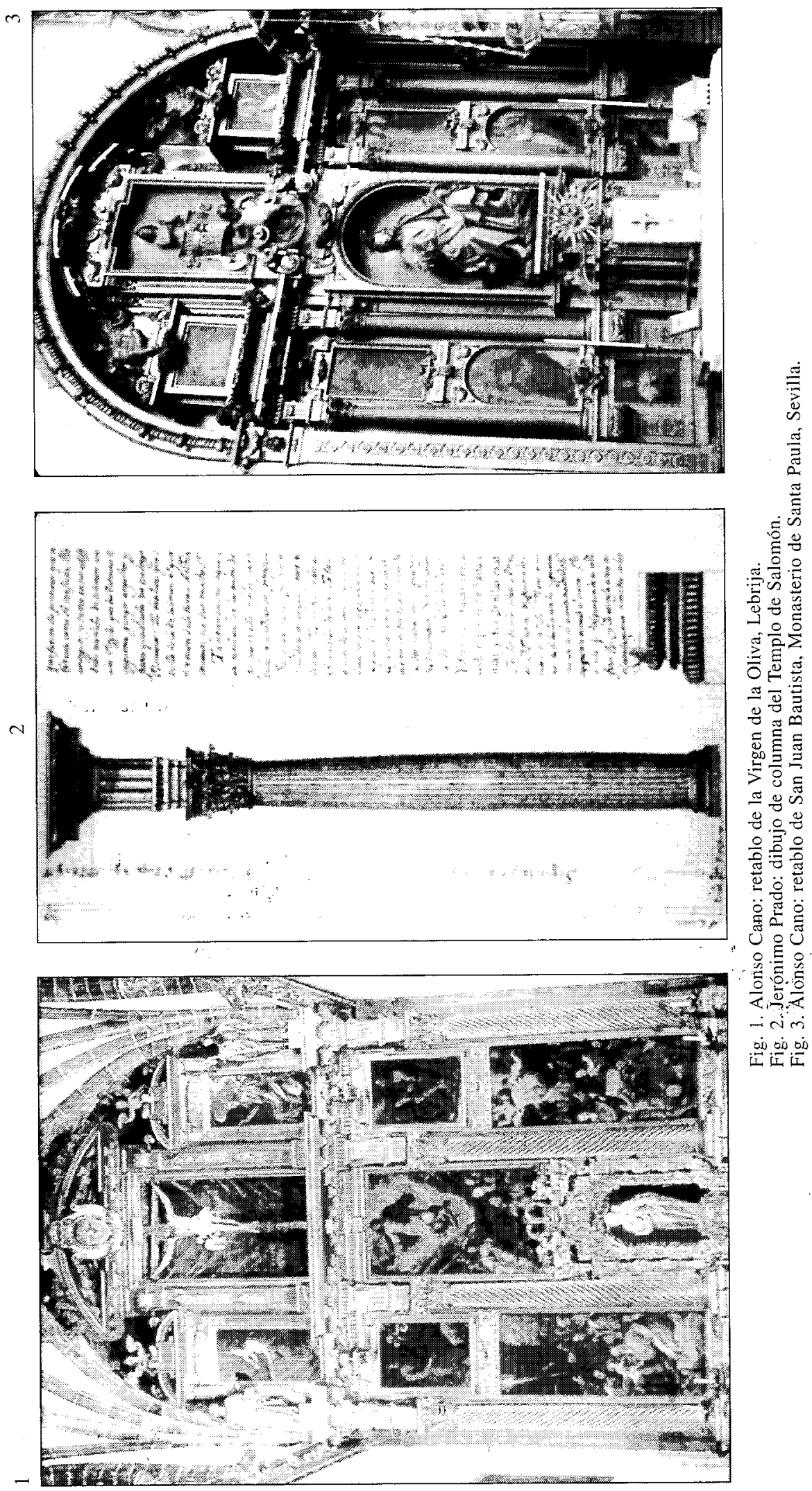

운 논

- $\mathrm{im}$

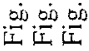


El retablo de la Virgen de la Oliva en Lebrija pasa por ser la obra más temprana y a la vez revolucionaria de Cano en el campo del ensamblaje. Sin embargo el uso de un orden único de columnas gigantes que atan entre sí basamento y ático y producen una fuerte sensación de unidad y coherencia, se encuentra en la obra de Alonso Matías, a quien consideré hace años como su precursor ${ }^{16}$. Pienso que las cuatro columnas de orden corintio, con su pedestal, fuste y capitel, están perfectamente proporcionadas y si producen la impresión de atirantamiento ello se debe a la utilización de los trozos de entablamento que gravitan sobre ellas. El contrato de este retablo, que firmó Miguel Cano y luego traspasó a su hijo, estipulaba que los fustes fueran de estrías derechas y, sin embargo, éstas se tallaron de forma helicoidal. Tampoco este rasgo era síntoma de vanguardismo frente a la normativa canónica ni algo peculiar de Cano, pues antes que él lo emplearon otros ensambladores sevillanos y, en particular, Diego López Bueno, con quien los dos Cano mantuvieron relaciones e intereses comunes. Alguien ha opinado recientemente que las estrías helicoidales podían conferir un aspecto salomónico a las columnas, pues en el primer tercio del siglo tallar los senos y protuberancias de la genuina columna salomónica resultaba difícil. En todo caso debía ser conocida en Sevilla la reconstrucción que del orden salomónico habían efectuado los jesuitas Jerónimo Prado y Juan Bautista de Villalpando. Pues bien, ninguno de los dos había propuesto como distintivo suyo el fuste con torsiones en espiral. En cambio ambos aislaron un trozo de entablamento sobre la columna, cuya cara anterior lleva los glifos característicos del orden dórico, pese a que sus demás componentes pertenecen al corintio. Cano debió conocer esta última fórmula, pues no sólo utilizó el trazo de entablamento aịslado sobre cada columna sino que talló, a pesar de que el capitel es corintio, glifos dóricos sobre sus caras anteriores. Pero se atuvo en esto no a los glifos pares y planos de Prado y Villalpando, sino a los recurvados que Vignola aconseja en la ménsula que sirve de soporte a las cornisas muy voladas ${ }^{17}$.

El retablo lateral de San Juan Evangelista, en la iglesia del monasterio sevillano de Santa Paula, se distingue, en contraste con la parquedad decorativa del de Lebrija, por el estallido ornamental, tanto más perceptible cuanto que es de pequeñas dimensiones y muy cercano a la vista del espectador. En él hace reiterada aparición la «hoja canesca», antepuesta a la cara anterior de una placa o conjunto de placas recortadas. Se ha querido ver, lo mismo en la placa que en la hoja, una invención original, y hasta entonces inédita, de Cano. Sin embargo las placas únicas o superpuestas aparecen profusamente en las láminas del tratado de Wendel Grapp, llamado Dietterlin, que, aunque publicado en 1598, debió llegar a conocimiento de los artistas españoles al finalizar la segunda o tercera década del xvIr. Lo menciona el ensamblador extremeño Salvador Muñoz quien, como veremos, se relacionó con Cano; lo poseía el maestro de obras madrileño José de Arroyo, en cuya almoneda de bienes lo adquirió Teodoro Ardemans; y tampoco era desconocido en librerías de artistas catalanes y levantinos ${ }^{18}$. Con todo el uso de placas recortadas por parte de Cano debió ser autóctono, trayendo probablemente su origen de los tacos encolados y engatillados del ámbito de la carpintería, de la ebanistería y del ensamblaje.

Por lo que hace a la «hoja canesca» o cogollo de hojas cartilaginosas — por lo tanto artifi-

\footnotetext{
15 Véase la nota 6; además Benito Navarrete Prieto, La pintura andaluza y sus fuentes grabadas, Fundación de apoyo a la Historia del Arte Hispánico, Madrid 1998, pp. 70-71; Alfonso E. Pérez Sánchez, «La pintura de Alonso Cano», Figuras e imágenes del Barroco, pp. 234-35.

16 Alfonso Rodríguez G. de Ceballos, «Alonso Matías, precursor de Cano», Centenario de Alonso Cano en Granada, I: Estudios, pp. 165-99.

17 Fernando Marías, «Alonso Cano y la columna salomónica», Figuras e Imágenes del Barroco, pp. 291-321.

18 Ramón Soler y Fábregat, «Libros de arte en bibliotecas de artistas españoles (siglos XVI y XVII): aproximación bibliográfica», Locus Amoenus, Universidad Autónoma de Barcelona, nº 1, 1996, pp. 145-64; ID., El libro de arte en España durante la Edad Moderna, ed.Tesea, Gijón 2000, pp. 88 y ss.
} 
ciales y no naturalistas-, unas veces superpuestas y enrolladas en volutas, otras extendidas en capas de contorno sinuoso y picudo, parecen proceder en última instancia de las volutas afrontadas en forma de $\mathrm{C}$ mayúscula que, en un comienzo, flanqueaban como orla el campo de un escudo heráldico, de una inscripción o de una divisa. Posteriormente fueron adquiriendo vida propia hasta convertirse en registro ornamental independiente. En su forma más simplificada se perciben ya en retablos y yeserías sevillanos de las primeras décadas del xvII, por ejemplo en los estucos diseñados por Herrera el Viejo para las iglesias de San Buenaventura y de San Hermenegildo. Acaso Cano las tomase de Herrera, estudiase o no en su taller, pero dando a sus contornos y dintornos mayor blandura y maleabilidad, propias del llamado «estilo cartilaginoso». En un grado de evolución más avanzada la «hoja canesca» guarda analogía con las yeserías del coro de la iglesia de Santa Paula, diseñadas hacia 1623 por López Bueno. En cualquier caso es menester encuadrar la génesis de este ornato en Cano dentro de la evolución del ornamento europeo de comienzos del Seiscientos hacia el que los estudiosos germanos han denominado «Ohrmuschelstil». Sin ser absolutamente iguales los cogollos de hojas canescas se parecen mucho, por ejemplo, a los del dibujante y grabador de Ausburgo Lucas Kilian, quien falleció en $1637^{19}$.

El retablo diseñado por nuestro artista para la parroquia madrileña de San Andrés hacia 1644 no se llevó a efecto, o porque carecía de taller o por otras causas que desconocemos, pero es uno de los más bellos y originales del granadino. Ahora bien tampoco se percibe en él síntoma ninguno de descoyuntamiento de proporciones ni de uso anticanónico de los órdenes, del corintio en concreto; al contrario, la distribución armónica de sus tres cuerpos es perfecta y sobre los capiteles corre un entablamento completo clásicamente mucho más correcto que el del retablo de Lebrija. Lo que destaca mayormente es el singular acoplamiento entre arquitectura y escultura y la abundancia y variedad de registros decorativos.

El dibujo para un retablo de San Juan de Dios en el Museo del Prado se ha pensado que lo hizo Cano entre 1640 y 1650 . Sin embargo este retablo coincide punto por punto con el que fue contratado y ejecutado en 1637 por Juan de Echalar según un diseño de Juan Gómez de Mora para el hospital de Antón Martín ${ }^{20}$. Es verosímil que cuando Cano llegó a Madrid en 1638 las pinturas de sus tableros con escenas de la vida del santo estuviesen aún por realizar y que se le adjudicasen entonces a él, con motivo de lo cual hiciese el dibujo en cuestión, cuyo estilo y trazo son indudablemente suyos. No así la estructura arquitectónica, sumamente regresiva si se la compara con la de los retablos de Lebrija y San Andrés.

También plantean problemas los dos retablos colaterales de la iglesia de la Magdalena de Getafe. El ensamblador y tallista Salvador Muñoz hizo desde luego el del lado de la epístola, dedicado a la Virgen de la Paz, y debió realizar el diseño del otro, consagrado al santo Nombre de Jesús, que llevó a efecto su discípulo y yerno Gabriel Vázquez. Cuando en 1646 se asentaron ambos retablos parece que Cano hizo únicamente sus tableros pintados ${ }^{21}$. De todas maneras en sendos retablos los segundos cuerpos y los áticos se desvían totalmente del estilo del primer piso, muy tradicional y conservador. Por el contrario en los cuerpos superiores aparecen muchos rasgos canescos: pilastras y machones cuyos capiteles han sido reemplazados por cogollos de hojas cartilaginosas así como guirnaldas, festones y colgantes de frutas. ¿Acaso

\footnotetext{
19 Rudolf Berliner, Modelos ornamentales de los siglos xv al xvII, Labor, Barcelona 1928, volumen de texto, pp. 6768; Alfonso Rodríguez G. de Ceballos, «Motivos ornamentales en la arquitectura de la península ibérica entre Manierismo y Barroco», Actas del XXIII Congreso Internacional de Historia del Arte, II, Universidad de Granada, Granada 1977 , pp. 560-67.

${ }_{20}$ Véase el contrato resumido en Mercedes Agulló y Cobo, Documentos sobre escultores, entalladores y ensambladores de los siglos XVI y XVII, Universidad de Valladolid, Valladolid 1978, pp. 59-60.

${ }_{21}$ Juan Manuel Cruz Valdovinos, «Varia canesca madrileña», A.E.A., LVIII, 1985, pp. 278-79.
} 
Cano modificó en algún momento las trazas de Salvador Muñoz o éste mismo modificó su estilo, amoldándolo al gusto de aquél en el trascurso de la ejecución?

El último retablo que el artista proyectó en Madrid durante el viaje de 1657, cuando ya se encontraba afincado como canónigo racionero en Granada, fue el de la capilla de San Diego en el convento franciscano de Santa María de Jesús en Alcalá de Henares. El precioso dibujo, en colección privada florentina, dado a conocer recientemente ${ }^{22}$, destaca una vez más no por la disposición poco ortodoxa de sus miembros arquitectónicos sino por su ponderado equilibrio entre arquiteçtura, escultura y pintura y por la variedad, abundancia e inventiva de sus molduras, adornos y registros decorativos, de los que se ofrecen - como es habitual en otros diseños de Cano- soluciones alternativas a elegir por el cliente. El espléndido proyecto no fue llevado a efecto por Cano, quien ya no se encontraba de asiento en la corte ni tenía taller y oficiales para ello. En la última etapa del artista, la granadina, que, aunque con interrupciones, alcanzó un considerable período de tiempo desde 1652 hasta su muerte en 1667, no hay constancia documental ni gráfica seguras de que ensamblase ningún retablo, intensamente ocupado como estaba en servir al celoso cabildo eclesiástico. No sabemos con certeza si el dibujo parcial de retablo, que se encuentra en la Kunsthalle de Hamburgo, y que H. Wethey consideró destinado al monasterio franciscano de San Antonio y San Diego, perteneció a dicha fase, pues la iglesia de este convento granadino, ya desaparecido, consta que se terminó de construir en fecha muy anterior, 1636 .

No me puedo extender sobre los proyectos arquitectónicos que diseñó Cano, además de los retablos, ni sobre sus dibujos ornamentales, puesto que son estudiados en otro artículo de esta misma revista. A los ya conocidos hay que sumar los contenidos en el álbum de Antonio García Reinoso, depositado en la Biblioteca Nacional, que son claramente suyos y algunos de los más hermosos que compuso ${ }^{23}$. Me permito únicamente algunas consideraciones sobre si en ellos se manifiestan rasgos heterodoxos y anticlásicos u otras novedades vanguardistas no englobadas en los repertorios tradicionales. Cano comenzó a interesarse por la columna salomónica genuina en un dibujo, hoy en la Biblioteca Nacional, donde aparece flanqueando a ambos lados una puerta o ventana, dibujo que se fecha en la década de 1650. Para entonces la columna salomónica de fuste con torsiones helicoidales había tomado carta de naturaleza en España y su uso había sido refrescado recientemente por los cartones de Rubens para los tapices eucarísticos de las Descalzas Reales, llegados a Madrid en 1648. Cano siguió en este dibujo el modelo rubensiano de cinco espiras frente al de seis, que podríamos llamar normativo a raíz de su divulgación por el tratado sobre los cinco órdenes de. Vignola, desde el punto de vista teórico, y por el baldaquino de Bernini desde el práctico. El capitel corintio que corona las columnas hace girar los enrrollamientos de sus caulículos no hacia afuera, como era lo habitual, sino hacia dentro, pudiendo derivar esta anomalía en Cano de su manejo de estampas de arquitectura de G.B.Montano y de Borromini ${ }^{24}$.

En otro dibujo de la Biblioteca Nacional, que representa probablemente el encasamento de un retablo, vuelve a hacer su aparición la columna salomónica, pero ahora más enana, de cuatro espiras. La predilección de Cano por el orden salomónico auténtico, no por el pseudosalomónico practicado en su juventud, fue característica de su fase madrileña en contacto con los círculos más cultivados de la corte. En Madrid pudo verlo, en efecto, ejecutado en algunos

\footnotetext{
22 Alfonso E. Pérez Sánchez, «Capilla de San Diego en el convento franciscano de Alcalá de Henares», Zurbarán. Catálogo de la Exposición, Museo Nacional del Prado, Madrid 1988, pp. 327-31.

2.3 Delfín Rodríguez Ruiz, «Album de Antonio García Reinoso (siglos XVI-XVII)», en Dibujos de arquitectura y orna mentación de la Biblioteca Nacional. Siglos XVI-xvI, Ministerio de Cultura, Biblioteca Nacional, Madrid 1991, pp. 312-63.

${ }^{24}$ Delfín Rodríguez Ruiz, «No importa, pues lo iço Cano. Dibujos y pinturas de un arquitecto legendario que sólo quiso ser recordado como escultor», Figuras e imágenes del Barroco, pp. 403-30.
} 

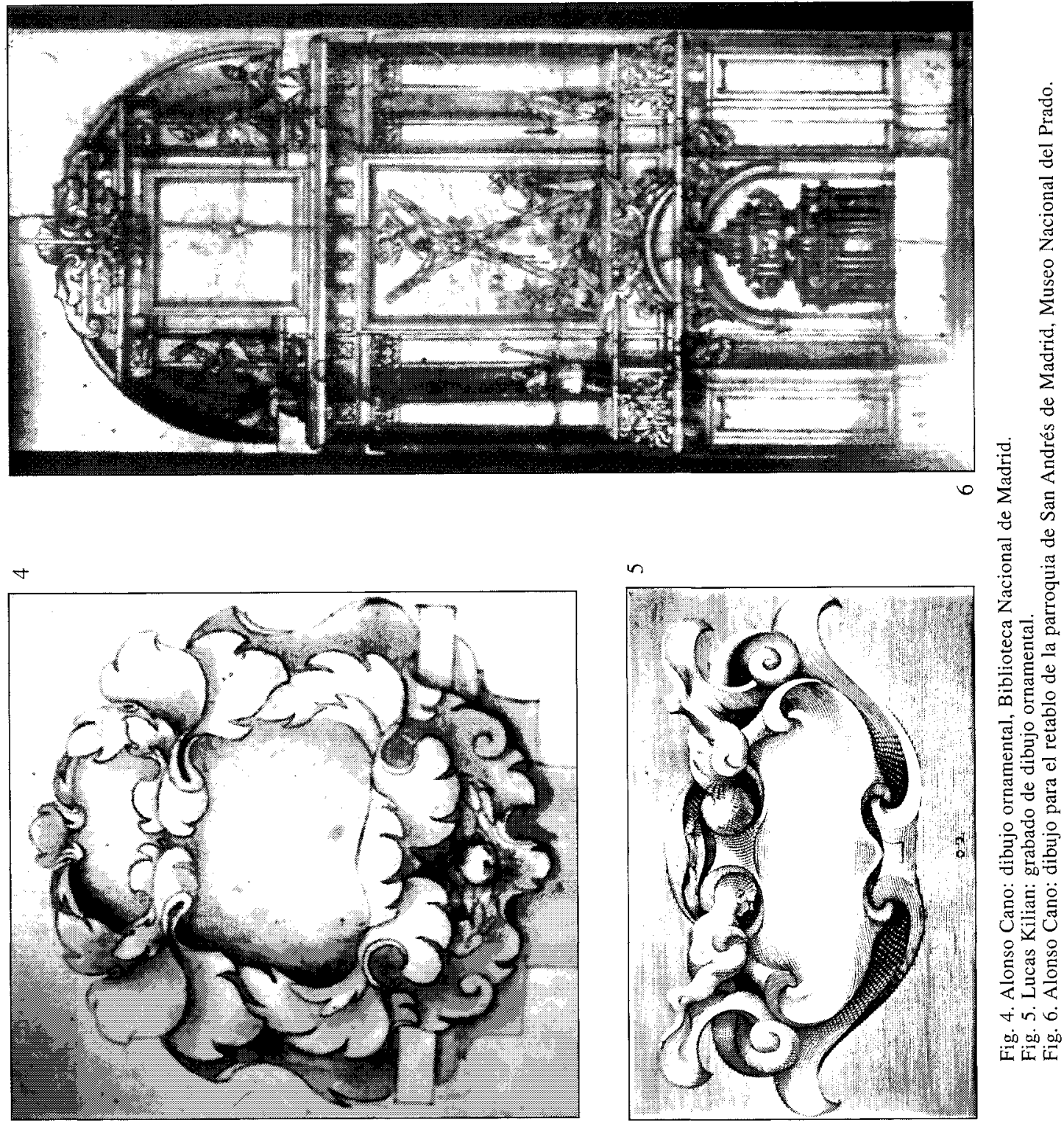

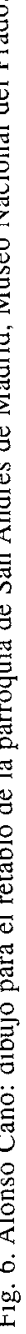


retablos anticipadores del gran ensamblador Pedro de la Torre, quien aconsejaba precisamente hacer los fustes de cinco vueltas ${ }^{25}$. De este mismo número de vueltas eran igualmente los fustes de las columnas salomónicas dibujadas por Cano en el proyecto, alternativo a los del mismo Pedro de la Torre y Francisco Bautista, para el trono de la Virgen del Sagrario de Toledo, proyecto que se guarda en el archivo de la Obra y Fábrica de la catedral primada ${ }^{26}$.

Nuestro artífice tuvo conocimiento de otro soporte arquitectónico singular, el estípite, pero ello no debe extrañar pues, aunque su uso masivo se popularizó en nuestro país a finales del xvil por obra de José de Churriguera y Pedro de Ribera, su existencia pertenecía a la antigüedad clásica y fue intensamente propagada a finales del Quinientos por innumerables tratadistas flamencos, alemanes y franceses sutilizando y especulando sobre los órdenes clásicos de arquitectura. En un diseño para un fuente monumental, acaso destinada a los jardines de la Casa de Campo o del Buen Retiro (colección Beruete), Cano situó estípites abstractos, a lo Miguel Angel, coronados por capiteles jónicos, a plomo de las pilastras toscanas del primer cuerpo. Estos estípites son la única nota un tanto excéntrica dentro de una estructura arquitectónica completamente ortodoxa, es más una estructura de tanta austeridad y sequedad ornamental que parece remitirnos a épocas pasadas.

Estípites vuelven a aparecer en otro diseño de la Biblioteca Nacional, que algunos estudiosos imaginaron era el proyecto preparatorio de la famosa puerta triunfal de Guadalajara, mientras que otros pensaron que se trataba del proyecto de tabernáculo eucarístico de la catedral de Málaga, encargado a Cano en 1666 por el obispo fray Juan de Santo Tomás. A nuestro entender no fue ni para una cosa ni para la otra, sino para el monumento de Jueves Santo de la iglesia de franciscanos de San Gil, próxima al Alcázar, adonde, según Díaz del Valle, acudían muchos artistas a estudiarlo y admirarlo ${ }^{27}$. Sea de ello lo que fuere, los estípites son aquí antropomórficos pues, en lugar de capitel, están coronados por cabezas de serafines. Pero ello no debe dar pie, como lo ha hecho algún estudioso recientemente, para hablar de un «orden seráfico», como si Cano hubiera inventado un orden arquitectónico nuevo que añadir a los cinco antiguos. Ya Juan de Caramuel llamó «orden paranínfico» a los soportes de cariátides y canéforas, lo cual en su tiempo no dejó de ser un neologismo pedante y sin sentido.

En algunos dibujos no arquitectónicos ni ornamentales sino preparatorios de encargos pictóricos concretos, por ejemplo la serie de once escenas de la vida de Santo Domingo de Guzmán para los lienzos que decoraron un día el claustro del monasterio granadino de Santa Cruz la Real (repartidos los dibujos entre el Museo del Prado, la Biblioteca Nacional y la Kunsthalle de Hamburgo), Cano enmarcó las escenas en amplios fondos de arquitectura. Pero en éstos se esmeró en graduar cuidadosamente los distintos planos del espacio y los términos de la perspectiva, trazándolos con regla y compás y marcándolos con un punzón antes de trazar las líneas con tinta, pero no en introducir novedades y licencias. Suelen ser efectivamente las arquitecturas de sus fondos de una simplicidad, sequedad y equilibrio de masas y volúmenes tales que retrotraen al espectador a estilos del inmediato pasado ${ }^{28}$.

Los fondos arquitectónicos de la serie de Santa Cruz son, por otra parte, contemporáneos de su actividad como arquitecto efectivo durante su última etapa granadina. Las obras de construcción que emprendió Cano entre 1652 y 1667 son las que más dudas y vacilaciones suscitan

\footnotetext{
25 «Y dichas columnas (salomónicas) han de tener cinco vueltas cada una... y en algunas partes donde se han ejecutado siendo del alto de seis... no han parecido bien, y esta opinión la observó en sus obras Pedro de la Torre, el mayor maestro que ha tenido España, que esto es notorio a todos los maestros de esta profesión»; Contrato para hacer en 1679 el retablo de la capilla de la Santa Cruz en la catedral de Palencia, en Jesús Urrea y Carlos Brasas, Inventario artístico de Palencia y su provincia, tomo II, Ministerio de Educación, Madrid 1980, p. 202.

26 Fernando Marías, artículo citado, pp. 345 y ss.

27 Epílogo y nomenclatura de algunos artífices, op.cit., p.338

28 Alonso Cano. Dibujos, Catálogo de la Exposición, números 36-37, pp. 168-79.
} 


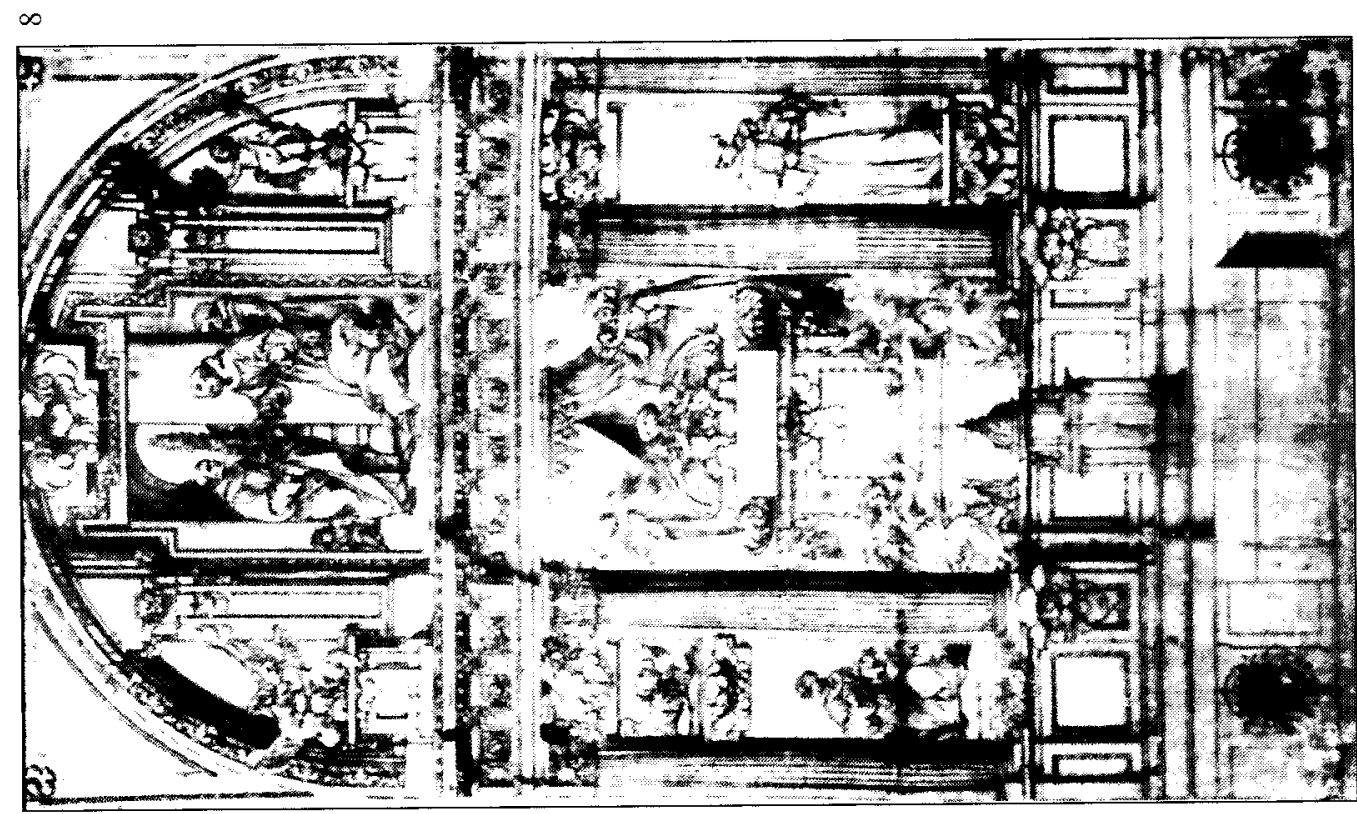

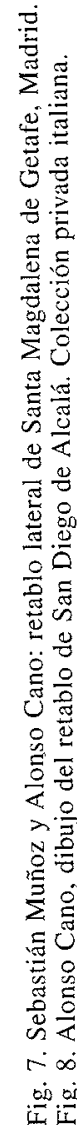


en el estudioso en el momento de querer calificar a su autor como genuino arquitecto. Son fundamentalmente tres: la iglesia del convento de franciscanas del Santo Angel Custodio, la del monasterio de agustinas del Corpus Christi (hoy parroquia de la Magdalena) y la fachada de la catedral, que vamos a examinar con la debida atención.

La primera se inició en 1653, recién llegado Cano a Granada, y se concluyó en 1661. Desgraciadamente fue saqueada y destruida por los franceses en 1810 , por lo que cuanto se ha escrito sobre ella se fundamenta en documentos escritos, no en el análisis visual ${ }^{29}$. Así sabemos por el cronista fray Tomás de Montalvo que Cano hizo su planta, que medía 108 pies de largo por 30 de ancho, cuya ejecución dejó en manos de Juan Luis Ortega, maestro de obras del arzobispado quien, en cualificación profesional, no parece haber pasado del grado de alarife o albañi $1^{30}$. A punto de inaugurarse en 1661 la obra «manifestó flaqueza en uno de los arcos de la capilla mayor y no se halló en Granada quien admitiese en corregirlo. Vino Fernando de Oviedo, maestro mayor de las fábricas de la ciudad de Sevilla y él lo remedió». De este desagradable accidente ha querido deducir R.Taylor que Cano no fue un arquitecto profesional, lo cual es absolutamente cierto, toda vez que, como se dijo anteriormente, hay que clasificarle en la categoría de arquitectos artistas. Nuestro personaje se dedicó, como era en él habitual, a los primores de la traza, dejando la construcción en manos del no muy competente Ortega, a quien hay que imputar errores en ese campo. Ya el cronista Montalvo lo expresó así en el ampuloso y retórico estilo de la época: «Empezó sus estudios el artífice en dar a luz una nueva planta que en corto espacio de tiempo no sólo delinease todos los primores de la arquitectura, sino que ostentase un no practicado nuevo rumbo que fuese empleo de la admiración. Reconocióse luego ser la idea aun en el dibujo una maravilla». Para Montalvo lo digno de admiración superlativa fue no la planimetría del templo, completamente convencional (cruz latina y nave única bordeada por capillas) sino la invención de un sexto orden de pilastras que articulaban los muros de la nave, pues escribe a continuación: «La ingeniosidad del artífice inventó una nueva nunca executada forma, adelantando esta sexta planta a las cinco que los arquitectos enumeran». Se refería con ello al uso de pilastras sin basa ni capitel, sustituido éste por golpes de hojas cartilaginosas, pilastras que aparecen en bastantes dibujos arquitectónicos de Cano y en el ático de los retablos de Getafe. Pues seguía expresándose de esta manera: «Sobresale el cuerpo del templo con ocho pilastras, cuatro a cada lado, sin basa ni capitel, su latitud una vara ( $83,60 \mathrm{cms}$.), termínase en la cornisa, formando en sus remates tarjas con hermosos roleos y follajes, y sobre este ornado estriba la cornisa alquitrabada que corresponde a lo exquisito de la fábrica».

La iglesia del monasterio de las Agustinas (la Magdalena) ni pudo ser trazada por Cano, quien había fallecido diez años antes, ni fue construida por Juan Luis Ortega, como afirmaba la tradición. Según demostró de manera fehaciente R.Taylor, fue levantada íntegramente por José Granados de la Barrera entre 1677 y $1686^{31}$. Sin embargo, a nuestro entender, es casi seguro que este arquitecto tomó como modelo el templo anterior del Santo Angel Custodio, entre otras razones porque la Magdalena es de tipo y estructura absolutamente madrileños y Granados no hay constancia de que hubiera estado nunca en la corte. Efectivamente tanto la disposición de la fachada con pórtico de triple hueco, el ritmo de articulación de sus pilastras, las torres que dejan entre medias un retranqueo para poder percibir la cúpula del crucero, cuanto la estructura del interior están copiados, con ligeras variantes, de la iglesia del Colegio Im-

\footnotetext{
${ }^{29}$ Fray Tomás de Montalvo, Chrónica del Convento del Santo Angel Custodio de Granada, Granada 1917, fragmentos publicados por F. J. Sánchez Cantón, Fuentes literarias..., V, Madrid 1941, pp. 511-12.

311 Lázaro Gila Medina, Maestros de cantería y albañilería en la Granada moderna según los escribanos de la ciudad, Colegio Notarial de Granada, Granada 2000, pp. 215-16.

31 Artículo citado en la nota 4.
} 


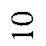

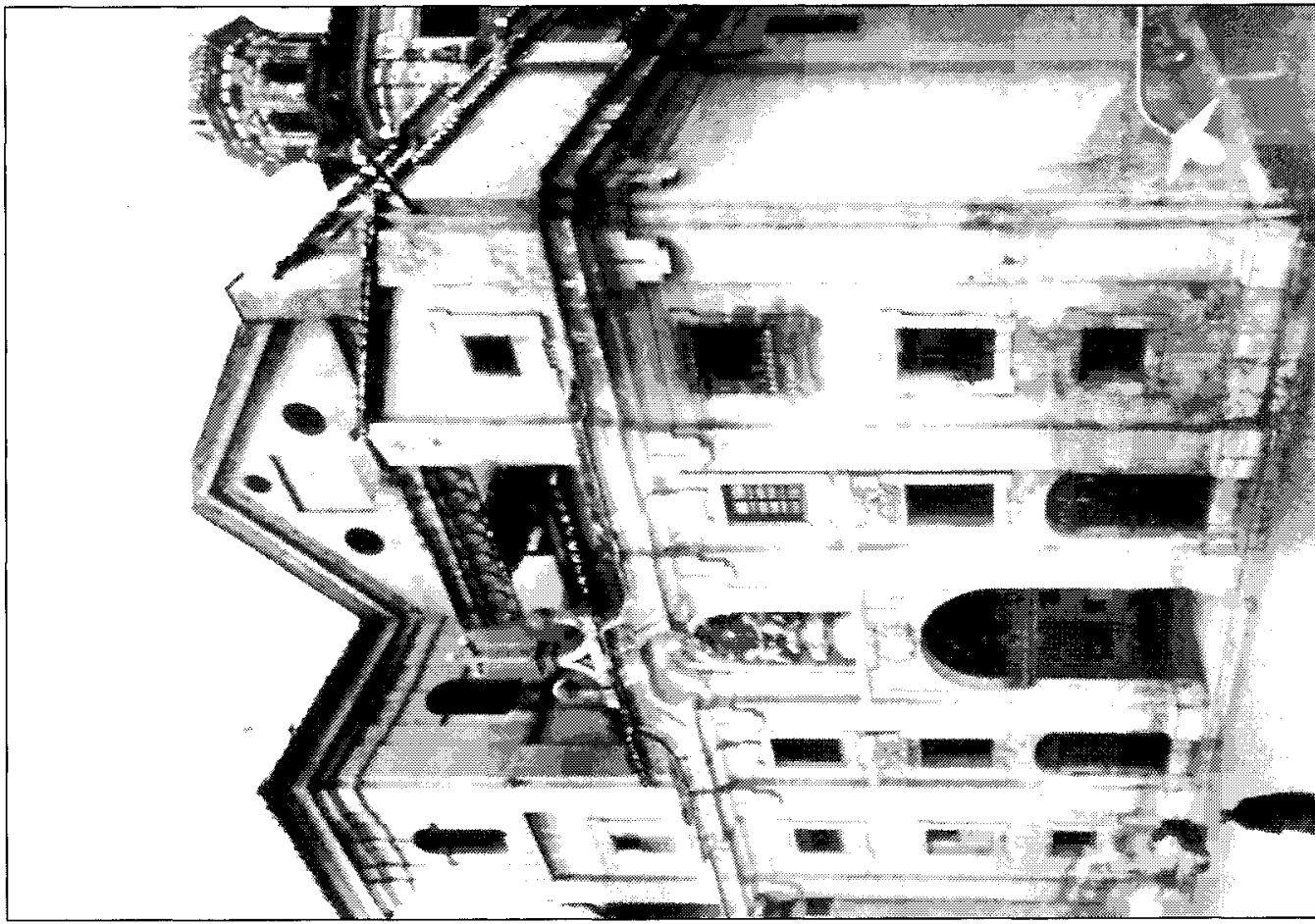

鸹

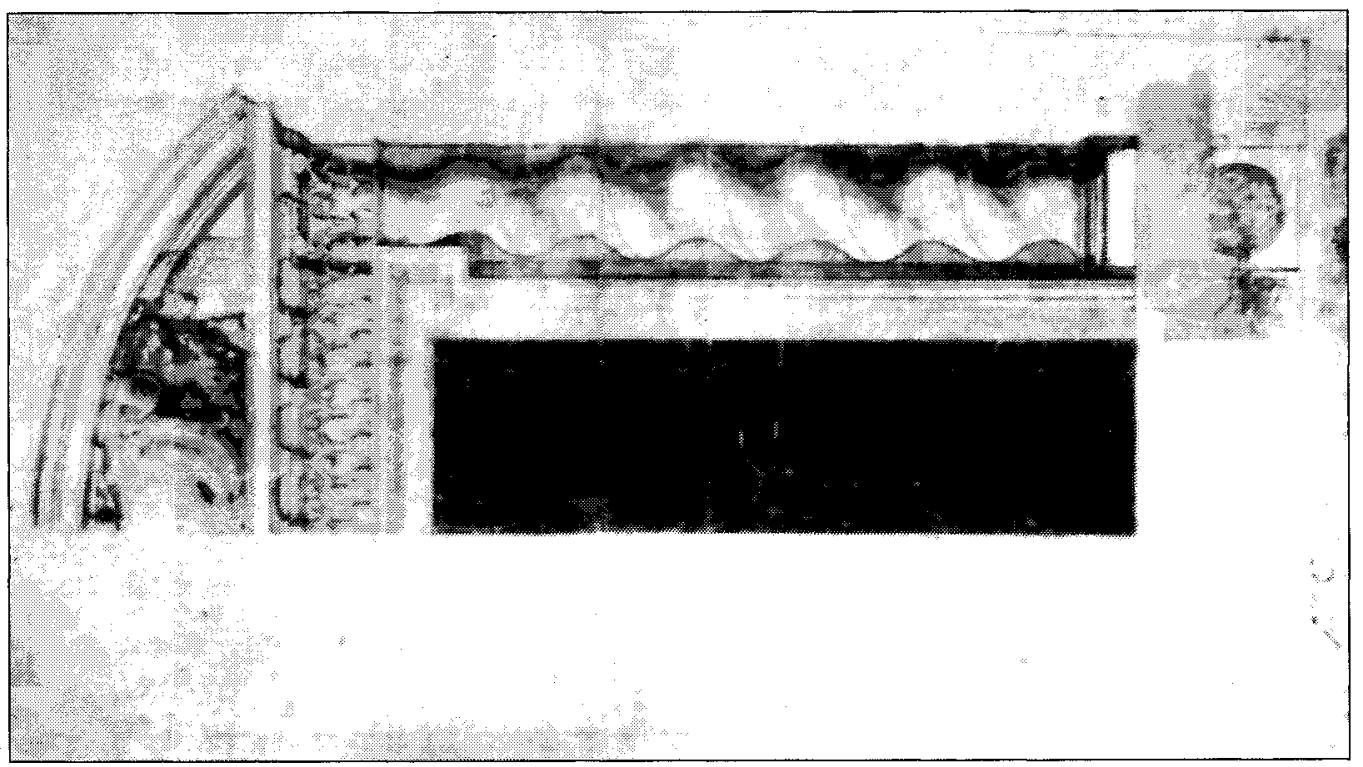


perial, actualmente Colegiata de San Isidro, que conoció muy bien Cano por haber realizado en ella importantes pinturas. Ahora bien todos estos rasgos debían encontrarse en la iglesia del Santo Angel Custodio diseñado por Cano.

La fachada occidental de la catedral de Granada merece ser estudiada sin prejuicio ni ideas preconcebidas a fin de aquilatar hasta qué punto participó en su proyectación y construcción nuestro artífice, ya que todo el mundo ha hecho hincapié en ella para afirmar rotundamente su originalidad como arquitecto. Repasemos primeramente, aunque de manera esquemática, lo que dice la documentación al respecto ${ }^{32}$. Rechazadas las trazas de otros maestros de obras, alguno venido de Madrid, el cabildo catedralicio examinó la presentada por el racionero Cano y, dándola por satisfactoria, nombró a éste maestro mayor de la obra, poniendo bajo su autoridad y control al aparejador Juan del Páramo y a los demás oficiales y canteros. El nombramiento tuvo lugar el 15 de mayo de 1667; pues bien el racionero falleció el 3 de septiembre, por lo cual sólo estuvo al frente de la obra cuatro meses escasos, lapso de tiempo que no daría sino para poner a punto los cimientos. Este hecho plantea el problema de si, sus sucesores introdujeron cambios y modificaciones importantes en tal grado que nos hace preguntar si la fachada que actualmente contemplamos es atribuible en su integridad a Cano.

En abril de 1668 visitó la obra del maestro toledano Bartolomé Zumbigo, quien informó al cabildo de que se estaba realizando acertadamente conforme a la traza aprobada. Se designó entonces maestro mayor al mencionado Granados de la Barrera, quien continuó la construcción hasta su muerte en 1685. Para entonces la fachada estaba levantada, al parecer, hasta el arranque del segundo cuerpo. Sustituyó a Granados como maestro mayor Melchor de Aguirre, quien prosiguió el segundo cuerpo hasta su remate, introduciendo variantes muy significativas. Fue él quien, a mi entender, hizo por su cuenta el óculo, bastante peregrino, del hueco central de dicho cuerpo en forma de estrella de dieciséis puntas ${ }^{33}$, ya que introdujo este pormenor en la fachada cuando solicitó permiso del cabildo para modificar la traza de Cano. Este, en efecto, debía haber previsto coronar cada una de las tres calles con sendos frontones triangulares, situado el central a mayor altura que los laterales. En cambio Aguirre cerró las calles con parapetos planos sobre los arcos superiores, dotándolos de acroteras y pináculos. La sustitución de los frontones por un cierre plano fue desacertada y produce una sensación desagradable.

Aparte de las anomalías señaladas es preciso advertir que, si bien Cano había previsto seguramente relieves de escultura, estatuas de bulto redondo y racimos de hojas cartilaginosas para adorno de la fachada, todo ello se incorporó muy tarde, incluso bastante después de la muerte de Aguirre acaecida en 1695. El cabildo hizo pregonar la ejecución de los denominados significativamente en las Actas Capitulares «caprichos», es decir las «hojas canescas», en 1771, ejecución que dejó mucho que desear, como ya lo advirtió R.Taylor, pues los follajes resultan bastos, secos y apergaminados frente a la blandura y esponjosidad con que los dibujaba Cano. El relieve del óculo sobre la puerta principal fue encargado a José Risueño en 1617 y los restantes relieves, tondos y esculturas fueron hechos a partir de 1781 por Miguel Verdiguier y su hijo Luis Pedro ${ }^{34}$.

\footnotetext{
${ }^{32}$ La documentación pertinente puede consultarse en: Antonio Gallego Burín, El Barroco Granadino, Real Academia de BB.AA. de San Fernando, Madrid 1956, pp. 137-38; Earl E. Rosenthal, The Cathedral of Granada. A Study in the Spanish Renaissance, Princeton University Press, New Jersey 1961, pp. 213-28; José Luis Pardo Orozco, Alonso Cano: documentación de las Actas Capitulares de la Catedral de Granada, Colección Textos y Documentos para Ia Historia del Arte, Diputación Provincial, Granada 1986.

33 Recientemente esta extraña forma estrellada ha tratado de ser explicada en el contexto iconográfico de toda la fachada; véase Emilio A. Villanueva Muñoz, «La fachada de la catedral de Granada: consideraciones simbólicas», Cuadernos de Arte. Universidad de Granada, n. ${ }^{\circ} 32,2001$, pp. 139-57.

34 Domingo Sánchez-Mesa Martín, «La portada de la catedral de Granada como el gran retablo barroco de Alonso Cano», Estudios de Literatura y Arte dedicados al profesor Emilio Orozco Diaz, III, Universidad y Caja de Ahorros de Granada, Granada 1979, pp. 307-22.
} 


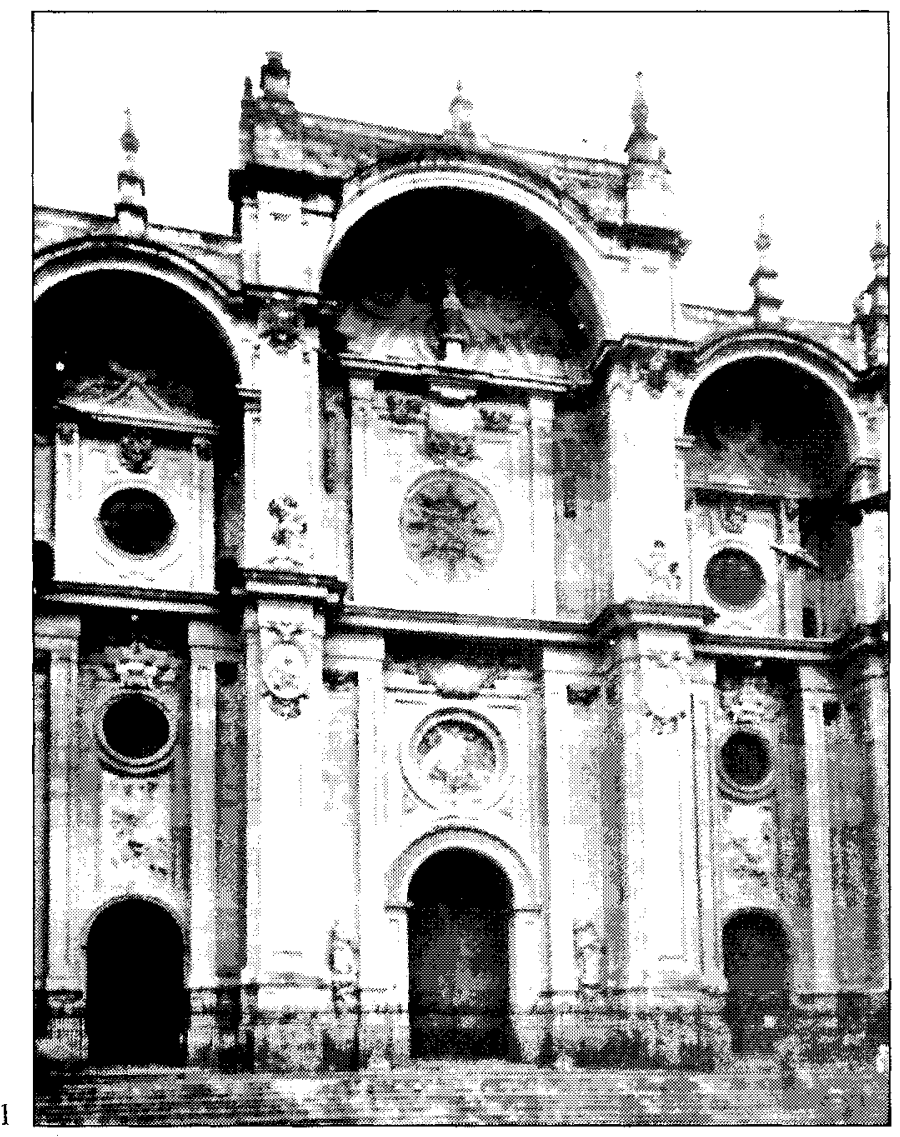

12

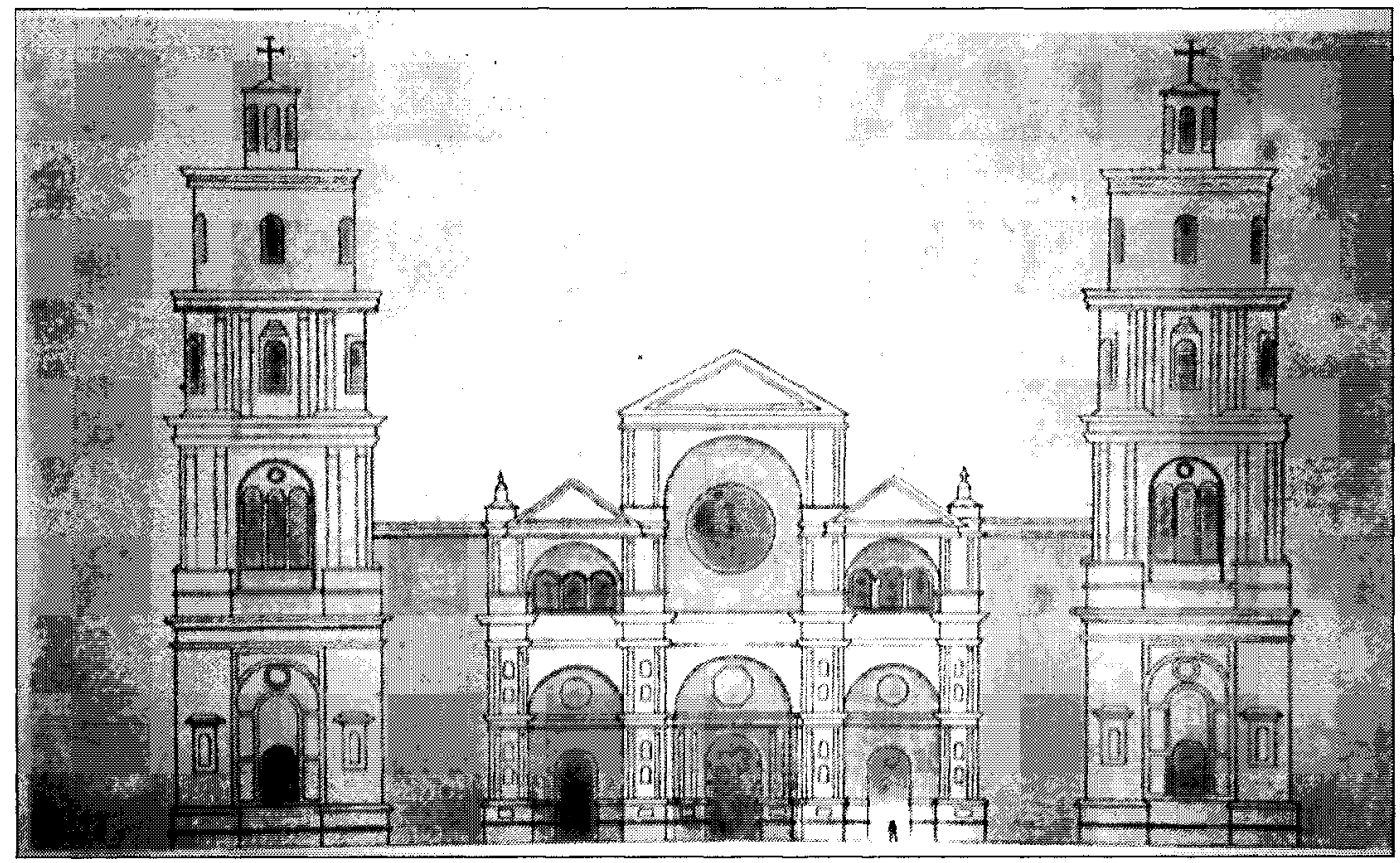

Fig. 11. Alonso Cano: fachada de la Catedral de Granada.

Fig. 12. Lázaro de Vejasco: proyecto de fachada de la Catedral de Granada. Reconstrucción de E. Rosenthal. 
¿Qué se puede, entonces, atribuir a Cano en la fachada? Probablemente toda su estructura arquitectónica; con seguridad la del primer cuerpo, con más dudas la del segundo, dadas las alteraciones y modificaciones incorporadas por Melchor Aguirre. Ahora bien dicha estructura debió estar muy condicionada por el proyecto primitivo de fachada debido en definitiva a Lázaro de Velasco en 1577, quien tradujo a su manera las ideas del propio Diego de Siloe. Es más, los pedestales de los cuatro machones o estribos que articulan todo el frontis se encontraban construidos y, al menos, la jamba de una de las puertas de ingreso aparece tallada en un tercio con una decøración que, por ser ya obsoleta, no se continuó ${ }^{35}$. El dibujo a ras de suelo de la planta de la catedral, realizado en 1594 por Juan de Vega y recientemente dado a conocer ${ }^{36}$, muestra el último machón del lado izquierdo con la proyección hacia adelante con que hoy se ve, factor que predeterminó la profundidad de los tres huecos de la fachada. Por consiguiente la intensa zona de sombra que aquella profundidad causa en estos huecos no es de ninguna manera un «efecto barroco» buscado deliberadamente por Cano, como se ha escrito con harta frecuencia, sino algo ya previsto en el Quinientos.

El esquema siloesco de fachada, realizado por Velasco y reconstruido por E.Rosenthal, constaba de dos cuerpos separados vigorosamente entre sí por una gruesa y proyectada cornisa. En el inferior se disponía el clásico motivo de arco de triunfo, es decir de tres huecos de igual altura terminados en arcos de medio punto, que cobijan las tres puertas de entrada. El piso superior funcionaba como un ático en el cual las tres calles tenían distintas alturas, la central mayor que las laterales, en ellas se abrían ventanas de iluminación bajo arcos también de medio punto, y estaban rematadas por sendos frontones triangulares ${ }^{37}$. Lo que debió hacer Cano fue desvirtuar el meditado equilibrio de cuerpos y calles pues, al suprimir o no destacar suficientemente la separación entre el piso inferior y el superior - sustituyendo la primitiva cornisa de separación por una imposta corrida-, y al prolongar el desarrollo de los estribos casi sin solución de continuidad hasta los tres arcos del segundo cuerpo, favoreció las proporciones verticales en altura a costa de las horizontales. Lo que posiblemente pretendió nuestro artista, al disparar vertiginosamente hacia arriba los tres arcos del motivo de arco triunfal siloesco, fue situarlos al mismo nivel de los que en el interior de la catedral sustentan las bóvedas de las naves. Asimismo los estribos atirantados se asemejan en su incontenible ascensión a los pilares compuestos que separan las naves del templo. Tanto es así que la fachada canesca en su totalidad actual produce la impresión de estar pensada para que el espectador se haga la ilusión de estar contemplando desde la calle la disposición interna del templo catedralicio. No se trata, por consiguiente, desde el punto de vista compositivo, de una fachada retablo, como a veces se ha escrito, sino más bien de una fachada pantalla ${ }^{38}$.

La fachada trazada por Cano ha merecido los juicios más dispares, desde el sumamente elogioso de G.Kubler, quien la considera «una de las más personales y geniales de toda la arquitectura hispánica», hasta el excesivamente severo F.Chueca Goitia, para quien «nada hay más lejos de la majestad clásica que esta fachada...Para un tema de estas dimensiones le faltaba a Cano la verdadera formación de arquitecto; el dilettante falló» ${ }^{39}$. En cualquier caso el artista granadino hubo de partir de un difícil pie forzado que condicionó su composición, privándole de la libertad necesaria para desplegar toda su fuerza creadora. Así hubo de trazar una

\footnotetext{
35 Véase Earl E. Rosenthal, op.cit., pp. 43-46.

36 Delfín Rodríguez Ruiz, «Sobre un dibujo inédito de la planta de la catedral de Granada en 1594», A.A.A., LXX, 1997, pp. 355-74

37 Véase la reconstrucción de la fachada de Lázaro de Velasco en E. Rosenthal, op. cit., ilustración 43.

38 Al hacer esta afirmación prescindo, claro está, de los aditamentos iconográficos.

39 George Kubler, Arquitectura española de los siglos xvil y xvin, Plus Ultra, Madrid 1957, p. 86; Fernando Chueca Goitia, «Cano y su influjo en la arquitectura barroca», Centenario de Alonso Cano en Granada, I: Estudios, p. 121.
} 
fachada de compromiso la cual - hay que decirlo en su elogio - fue muy respetuosa con lo construido en la catedral por Siloe y sus sucesores sin renunciar a ser moderna. Por otro lado los defectos que hoy pueda presentar son seguramente imputables a quienes materializaron su proyecto, que él no pudo controlar personal y directamente. 